\title{
Del populismo marxista al postmarxista: la trayectoria de Ernesto Laclau en la Izquierda Nacional (1963-2013)
}

\author{
Omar Acha
}

(CONICET - UBA)

\section{Introducción}

Ernesto Laclau es un renombrado teórico de la política cuya ubicación en el panorama intelectual actual se identifica con el postmarxismo y la elaboración de un modelo formalista del populismo. Su análisis ha sido calificado, con razón, de original e innovador. Sin desmedro de ello explicaré que durante una trayectoria que ya tiene más de medio siglo su agenda nocional ha persistido anudada a la critica populista del socialismo marxista. Primero en una concepción politicista y frentista de la política revolucionaria, y luego en un postmarxismo discursivo y populista. Su característica ha sido, entonces, la continuidad de los problemas de un pensamiento. La adhesión a las ideas de Jorge Abelardo Ramos o las lecturas de Gramsci, Wittgenstein y Lacan fueron accesorias a un mismo trance político: el intríngulis de la Izquierda Nacional en su propósito de construir una política transformadora que esté, no obstante, subordinada a un proyecto hegemónico nacional-capitalista encarnado por el peronismo. Por eso la persistencia no se verifica solo en el plano conceptual sino también en el político, donde la supeditación a alguna modulación del peronismo ha constituido la brújula tanto de su critica de la práctica revolucionaria como de la pretendida lucidez en la construcción hegemónica.

Una diferencia notoria del Laclau maduro con las concepciones más tempranas de la Izquierda Nacional, en cambio, es la resignación de toda crítica radical del capitalismo, devenida inviable debido a la "imposibilidad" de la sociedad y el carácter "totalizante" de atribuirle una "lógica". En tal sentido la trayectoria laclauiana acompañó el curso de buena parte de su generación intelectual, de la revolución a la reforma, del marxismo al postmarxismo, de la economía a la política, aunque conservando el núcleo básico de la estrategia populista: su incapacidad 
para generar una opción política que posibilite una proyección hegemónica anticapitalista de la clase trabajadora y los movimientos sociales.

La primera sección de este trabajo reconstruye las décadas iniciales del derrotero político e intelectual de Laclau desde su ingreso a la Izquierda Nacional en 1963 hasta la publicación del libro Politica e ideología en la teoría marxista (1978). La segunda sección analiza los virajes conceptuales que generaron el programa postmarxista de Hegemonía y estrategia socialista (1985) y sobre todo de Nuevas reflexiones sobre la revolución de nuestro tiempo (1990), donde se detallan los alcances de la critica laclauiana de Marx. En la tercera sección se estudia el uso del postestructuralismo en la fundación de La razón populista (2005), texto que confirma la deriva subalterna respecto a las variantes reformistas y populistas. Las conclusiones extraen derivaciones de la trayectoria de Laclau como intelectual de la Izquierda Nacional.

\section{De Jorge Abelardo Ramos a la teoria del populismo}

Ernesto Laclau nació en Buenos Aires, el 6 de octubre de 1935. Los datos biográficos son relevantes para su construcción subjetiva. El padre de Laclau fue importante en su definición como sujeto. No solo por las sedimentaciones sociológicas de un capital social y simbólico que lo predispuso a ser un intelectual "reconocido", sino también por los rasgos populistas de su forma mentis. Ernesto Laclau padre (1896-1985) fue un abogado radical-yrigoyenista con inquietudes lectoras, cuyas inclinaciones protopopulistas no lo privaron de cultivar amistades liberales (Laclau [p], 1921 y 1928). Estudió en la elitista Facultad de Derecho y Ciencias Sociales de la Universidad de Buenos Aires, fue representante legal de firmas importantes como el Banco de Nápoles y la Compañía de Navegación Italiana. Comisionado municipal en su Baradero natal a principios de los años 1940, ocupó un cargo público como presidente del Instituto Nacional de Previsión Social en 1956 y más tarde en el Servicio Exterior de la Nación.

Cuando el joven Laclau ingresó a la Universidad de Buenos Aires para estudiar historia, en 1954, se ligó con los sectores estudiantiles progresistas. En 1955 vio con buenos ojos el golpe cívico-militar antiperonista y participó en los grupos fubistas que promovieron la candidatura de José Luis Romero al rectorado de la Universidad porteña a fines de 1955. En esa misma línea de activismo se vinculó con los sectores de izquierda del Partido Socialista y militó con los grupos juveniles que fracturaron la vieja organización justista en 1958. Tras el liderazgo de Abel Latendorf, Laclau se integró al Partido Socialista Argentino (PSA). Como sucedió con otros integrantes de la juventud socialista, el carácter autoritario de la Revolución Libertadora, el desengaño del frondizismo y la confirma- 
ción del peronismo en la clase obrera, indujeron en el joven Laclau una revisión de su actitud hacia el populismo. En el órgano juvenil del PSA, Situación, publicó uno de sus primeros textos en que coincidieron -todavía vacilantes- la prosa académica y la preocupación política (Laclau, 1960). Luego de sostener la candidatura a senador de Alfredo Palacios en febrero de 1961, la Juventud rompió con la dirigencia partidaria y constituyó el Partido Socialista de Vanguardia (Tortti, 2009).

Ya autodefinido "marxista" desde fines de la década de 1950, comenzó a producir sus primeros textos en discusión con la sociología de la modernización y la vigorosa entrada de la historiografia de Annales. A propósito de la noción de mentalidad estable supuesta por la óptica annaliste, Laclau afirmó que "el marxismo representa la única tentativa válida, hasta el presente, de ligar la significación peculiar de un momento del tiempo con la totalidad de la historia humana" (Laclau, 1963: 98). Este fue un primer rasgo de cómo entendió Laclau el marxismo: como una teoría general de la historia, cuyas categorias eran útiles para todas las formaciones sociales complejas.

Entretanto la fluencia ideológica de la época en el panorama de la izquierda argentina planteó una decisión. Próximo al socialismo reformista, Laclau también se acercó al abanico nacionalista revolucionario en que se impuso un debate sobre el peronismo. Jorge Abelardo Ramos (1921-1994) cautivó al joven Laclau por su versatilidad retórica ante el peronismo, con el que había colaborado entre 1947 y 1955. La Izquierda Nacional había planteado un "apoyo crítico" sin resignar la construcción de una organización "obrera" que una vez consumados los objetivos de la revolución nacional impulsara -de acuerdo a una singular interpretación de la "permanencia" trotskista- el pasaje a la revolución socialista. En dicha estrategia era por entonces crucial definir que la meta planteada se ordenaba en un "frente nacional" de carácter antiimperialista en el que debían confluir todas las fuerzas "nacionales" (Herrera, 2011). El obrerismo y el revolucionarismo eran calificados como un "ultraizquierdismo" deudor de categorias foráneas, incapaz de comprender la estrategia adecuada para un país "semicolonial". Por lo tanto esta variante populista de la izquierda no debería ser confundida con la izquierda peronista que pregona su adhesión irrestricta al movimiento liderado por Perón. ${ }^{1}$

A pesar de que durante el primer peronismo el núcleo de la Izquierda Nacional solo adquirió alguna relevancia en su participación dentro del filoperonista Partido Socialista de la Revolución Nacional, la concepción

1. Sobre la Izquierda Nacional esperamos los resultados de investigaciones actualmente en curso, prometedoras de conocimientos más sólidos que los existentes, deudores de enfoques elitistas propios de una historia de las ideas sin dimensiones socioculturales: Methol Ferré (1961), Galasso (1983 y 2007), Regali (2012). 
política no fue rediscutida después de 1955. El Partido Socialista de la Izquierda Nacional (PSIN) fue fundado en mayo de 1962 con el liderazgo de Ramos y Jorge Enea Spilimbergo (1928-2004). Su consigna principal promovió añadir una cuarta "bandera" a las tradicionales del peronismo (justicia social, independencia económica, soberanía política): "gobierno obrero y popular". Laclau se integró al mismo en diciembre de 1963 con un núcleo de estudiantes provenientes de la Facultad de Filosofia y Letras, como Ana Lía Payró, Adriana Puiggrós, Félix Gustavo Schuster y Blas Alberti, cuya agrupación, el Frente de Acción Universitaria, presidió. En el activismo universitario Laclau llegó a conducir el Centro de Estudiantes de la Facultad de Filosofia y Letras. Durante cinco años activó en el PSIN integrando sus cuadros dirigentes, publicó en la revista teórica Izquierda Nacional y dirigió hasta 1966 el órgano Lucha Obrera, cuyo destinatario imaginado fue la juventud.

El PSIN impugnó toda estrategia de izquierda particularista, obrerista e inmediatamente revolucionaria. Esa idea pueril de la politica conduciria al aislamiento e incluso a posiciones reaccionarias como en el antiperonismo de izquierda (Spilimbergo, 1962; Ramos, 1964). El desafio consistía en tender el puente entre las tareas democráticas de la revolución nacional y la lucha socialista que exigía la guía de una "clase obrera autónoma" o "sectores populares autónomos" (Laclau, 1964b y 1964e). Constituir esa guía entrañaba la edificación de un frente entre la clase obrera y la pequeña burguesía, especialmente en su fracción estudiantil (Laclau, 1964a y 1964d). El pasaje de lo democrático a lo nacional se ordenaba en la confrontación de las "clases fundamentales" que no eran el proletariado y la burguesía -un error de la "izquierda cipaya" ajena a la "cuestión nacional" en un país semi-colonial- sino la clase obrera y la oligarquía (Laclau, 1965b).

La carrera académica de Laclau no se vio afectada por el activismo político. Obtuvo su título de licenciado en Historia en 1964 y el mismo año consiguió una beca doctoral del Consejo Nacional de Investigaciones Científicas y Técnicas. En 1966 fue designado profesor de historia en la Universidad Nacional de Tucumán, puesto que abandonó al año siguiente para revistar en la planta de investigación del Instituto Di Tella (Bergel, Canavese y Tossounian, 2004-2005).

Como sucedió en todas las organizaciones de la izquierda argentina, a lo largo de 1968 se produjo un conflicto entre el grupo juvenil y la vieja guardia. La tensión se extendió hasta noviembre de 1968, momento en que el sector juvenil fue expulsado del PSIN en razón de "desviaciones ideológicas", una acusación que ocultaba mal el enfrentamiento por primacías burocráticas entre la vieja y nueva generaciones. Laclau y otros jóvenes respondieron haciendo circular una carta donde cuestionaron el "sectarismo" partidario y la ausencia de una politica de intervención 
concreta, situación que condenaba a la organización a "vegetar" externa al movimiento obrero y estudiantil. En el recuerdo de Laclau (2012) la diferencia residió en la persistencia de Ramos en el modelo de un partido de corte leninista. No obstante la ruptura, el paso por el PSIN dejó las huellas indelebles en el todavía joven intelectual.

El marxismo de Laclau había consolidado por entonces un rasgo comunicable con el antes referido uso del marxismo como teoría general de la historia: la definición de un modo de producción dominante para determinar las "tareas" de una época. La politica de la Izquierda Nacional heredó esa inclinación de las discusiones intertrotskistas de los años 30 y 40, particularmente sobre la "cuestión agraria". En el lenguaje de la época se trataba de "caracterizar" una sociedad para extraer una estrategia correspondiente. Si bien los conceptos carecian de una formulación completa y precisa, la Izquierda Nacional contaba en su haber con especificaciones sobre la sociedad latinoamericana y argentina. En primer lugar, América Latina había heredado dos secuelas de la ruptura colonial: la "balcanización" de la "nación latinoamericana" y el sometimiento "semicolonial" al "imperialismo". La tarea derivada de esa definición fue que el programa socialista debía propender a una "liberación" del imperialismo, solo asequible a través de un proceso industrializador sostenido en la clase trabajadora, la burguesía nacional y sectores progresivos de las clases medias, campesinos y fracciones de la corporación militar. El peronismo, como expresión popular del programa industrializador y antiimperialista debía ser apoyado "críticamente" desde la independencia partidaria e ideológica de una organización que representara los intereses socialistas de la clase obrera (Belloni, 1960). Economicismo, clasismo y politicismo convivian ambiguamente en el pensamiento de la Izquierda Nacional.

La más sofisticada justificación de la política del "frente nacional" descansó en la teoria de la renta diferencial que Jorge E. Spilimbergo enunció en diversas oportunidades antes de que Laclau la trasladara al debate sobre los "modos de producción" en la segunda mitad de los años $60 .^{2}$ La más importante seguramente fue en el documento "Clase obrera y poder", aprobado en el congreso del PSIN realizado en Villa Allende, Córdoba, en agosto de 1964. Spilimbergo señaló que la inserción argentina en el orden mundial dominado por el imperialismo mantenía subordinado al país transfiriendo, sin embargo, un segmento del plusvalor expropiado a la clase obrera de los países centrales. Ésta pasaba a las arcas de la burguesía terrateniente local beneficiada por

2. La revista Izquierda Nacional reprodujo en 1966 el debate entre Rodolfo Puiggrós y André Gunder Frank desarrollado el año anterior en México sobre los "modos de producción". 
la extraordinaria feracidad de la pampa húmeda. El resultado era el estancamiento de la industrialización local debido a la división internacional del trabajo y la complicidad de la oligarquía con el imperialismo (2010 [1964]).

Laclau retomó este planteo y lo extendió, introduciendo nuevos elementos, a una discusión más amplia sobre América Latina. En discordancia tanto con la tesis de un subcontinente lastrado por "rémoras" feudales como con la tesis opuesta de un espacio llanamente capitalista, Laclau examinó las opciones recusando su común base "circulacionista" y propuso un análisis holístico donde no se perdiera de vista el proceso productivo. Distinguió althusserianamente entre el concepto abstracto de "modo de producción" de la más concreta noción de "sistema económico" donde se pueden reconocer varios modos de producción en una diversidad de interrelaciones. Su análisis coadyuvó a la segunda secuencia del debate en los años 70 donde se avanzó en el plano empírico para dirimir, sin embargo, alternativas similares (Laclau, 1969 y 1971).

Invitado por Eric J. Hobsbawm para seguir estudios doctorales en Inglaterra, Laclau abandonó sus perspectivas académicas en la Argentina con el objetivo de realizar una investigación empírica sobre la evolución del capitalismo local durante el siglo XIX. Se benefició entonces de una beca del St. Anthony College, en Oxford (1969-1972). En 1973 obtuvo un cargo (fellowship) de teoria politica en el Department of Government de la Universidad de Essex. Poco afecto a las fatigas historiográficas de largo aliento, se inclinó a obtener un doctorado sur travaux, logrado en 1977, y se empeñó en los estudios teóricos que lo hicieron célebre en el mundo intelectual.

Mientras tanto, en la Argentina, la Izquierda Nacional siguió un derrotero declinante, sin lograr arraigo en fracciones obreras o populares. En las elecciones presidenciales de marzo de 1973 intervino con su nuevo partido, el Frente de Izquierda Popular (FIP, fundado en noviembre de 1971), postulando a Ramos en competencia con la fórmula peronista Cámpora-Solano Lima. En las realizadas pocos meses más tarde, el FIP renunció a su fórmula y apoyó el tándem Perón-Perón, obteniendo casi 900.000 votos principalmente de sectores medios urbanos. Sin importancia política, luego de la muerte de Perón el FIP se alineó con el gobierno de Isabel Perón. Su realidad política había concluido. Paradójicamente, la exigua vida política de la Izquierda Nacional fue posible solo mientras el peronismo estuviera fuera del poder; cuando el peronismo lo detentaba, el discurso de la Izquierda Nacional devenía inaudible, irrelevante o utilizable por las élites peronistas. Su frágil dinamismo, exclusivamente propagandístico y editorial. En Essex, lejos de un escenario al que jamás quiso volver definitivamente, Laclau perseveró en 
lo decisivo de sus antiguas convicciones, con otras palabras, con otros libros. No lo hizo, empero, sin mutaciones decisivas.

Su libro de 1978, Politica e ideología en la teoría marxista, fue una formación de compromiso en un pasaje conceptual que lo retenía aún en los arrabales del marxismo. De ese volumen se suele recordar el cuarto ensayo "Hacia una teoría del populismo". Se subraya que la dimensión discursiva de la construcción subjetiva continuaba ligada a un ordenamiento de clase, nexo esencialista quebrado definitivamente en Hegemonia y estrategia socialista. No obstante el segundo ensayo sobre "La especificidad de lo político" tiene una significación mayor pues destaca un giro decisivo que adelanta temas timidamente presentes en el cuarto estudio. Al cuestionar una sobredeterminación estructural, explora la factibilidad de pensar lo político como otra cosa que una "superestructura"; la deriva hacia el debate sobre el concepto de modo de producción confirma que Laclau tiene en mente el intríngulis althusseriano de teorizar no hegeliana ni unicausalmente la metáfora marxiana del "Prefacio" de 1859. En el tercer ensayo, "Fascismo e ideología”, al examinar la teoría poulantziana de la política, Laclau critica su "reduccionismo de clase" y la endeble fundamentación en una "última instancia" que, otra vez althusserianamente, "nunca llega". Pareciera que el propio Althusser y sus seguidores no se hubieran atrevido a extraer todas las conclusiones del concepto de "sobredeterminación" pues reincidian en arraigar las explicaciones en una base económica y de clase. El déficit del estudio de Poulantzas sobre el fascismo residió en que no pudo captar "el carácter no clasista de las interpelaciones populares del fascismo" en un continuum de la práctica identificante que alcanza hasta el socialismo (Laclau, 1978: 163). Laclau se contiene al señalar que la diferencia con el socialismo consiste en que éste tiende a inclinar la mencionada interpelación "popular" a la revolución obrera. Fue esa característica, inexplicada por el autor, la que conduciría al postmarxismo. No sostengo que en ese ensayo estaba in nuce el libro publicado en 1985 junto a Chantal Mouffe. Me refiero a que el problema teórico para romper el nexo entre política y economía ya estaba presente en 1978. La misma estructura argumentativa singulariza al ensayo sobre el "populismo". Alli afirma que el socialismo, en la medida en que antagoniza al bloque dominado contra el bloque dominante, eleva la interpelación del "pueblo" a "la forma más alta y radical de "populismo" (Laclau, 1978: 231).

Mientras tanto los debates sobre el eurocomunismo, la "crisis del marxismo", el agotamiento de la propuesta althusseriana de conciliar la última instancia económica con la autonomía relativa de los "niveles", el avance del postmodernismo, fueron alterando el "espiritu de la época", no solo para Laclau. Toda una generación de intelectuales de izquierda 
experimentó un viraje que no fue solo teórico y político. Laclau no fue el único que en esos años hizo de Antonio Gramsci un postmarxista adalid de la "democracia", presuntamente incomprendida por el reduccionismo clasista marxista. ${ }^{3}$

\section{Postmarxismo y subversión de la metafísica}

El postmarxismo tiene varios orígenes teóricos. Su rasgo fundamental es la detección en Marx de una insuficiencia conceptual que reduce el ámbito de la experiencia a un fundamento, el que para ser tal debe ser único, indubitable, en fin, metafísico. En general, la alternativa "post" suele provenir de una multiplicación de instancias donde se constituyen las prácticas. ${ }^{4}$ Por ejemplo, lo hicieron Jürgen Habermas en Conocimiento e interés (1968) al oponer la dimensión interaccionalcomunicativa al paradigma del trabajo, y Cornelius Castoriadis en La institución imaginaria de la sociedad (1975) al sostener la dualidad de pensamiento y habla por una parte (legein), y acción y producción por otra (teukein). Pero el postmarxismo también tiene una procedencia sociológico-política con Claude Lefort, cuyo libro La invención democrática (1981) plantea la caída de los fundamentos de la política con el derrumbe de los Estados soberanos del Antiguo Régimen. La democracia carece de centro o soporte que no sea el de una invocación contingente, y finalmente vacía del "pueblo". Intentar definir un sujeto sustancial de la politica "moderna" es contener el carácter postfundacional de la democracia. La política opera sin fundamentos, emerge en procedimientos contingentes de institución precaria y controversial (Marchart, 2009). $\mathrm{El}$ postmarxismo laclauiano comparte con el análisis de Lefort un "gran relato" sobre la nueva época inaugurada por la "democracia" en tanto caída de la metafísica (de la sustancia o de la garantía) y habilitación de una apertura "radical". ${ }^{5}$

La pugna contra el fundamento es lo que estructura la discusión en el libro originario del postmarxismo, Hegemonía y estrategia socialista (Laclau y Mouffe, 2004 [1985]). Aparecido en la editorial de la New Left Review, Verso, desencadenó una amplia discusión entre sus filas. ${ }^{6}$ La

3. Portantiero (1983), Mouffe, ed. (1979).

4. En la espera de una buena historia del postmarxismo: Sim (2000), Therborn (2008).

5. Boucher (2008: cap. 2); sobre las dimensiones democrático-liberales del libro de 1985: Smith (1998); expresiones posteriores en Laclau (2000: 144; 2002: esp. 98-99).

6. Geras (1987 y 1988), Laclau y Mouffe (1987), Mouzelis (1988); participó en el debate Meiksins Wood (1986) y otras discusiones se realizaron en América Latina: Borón (1996). 
idea fuerte del libro consistió en la evacuación de todo fundamento de la política socialista, atribuida al marxismo "clásico" (el término es de Laclau), de una "positividad" social, económica o de clase. La política emerge en cambio como negociación de una "negatividad" no dialectizable por cuanto no es un movimiento "puesto" por una totalidad especulativa (para Laclau allí convergen tanto el Espíritu hegeliano como la Historia marxista). Encarnó en el plano filosófico una versión en teoría política del "giro lingüístico" característico de la época.

Conviene destacar aquí la estatura cognitiva de la teoría laclauiana de la "imposible sociedad", esto es, su crítica de lo social como totalidad cerrada y autosuficiente en sus determinaciones. Aunque Laclau haya sido muy claro al establecer que su impugnación de la noción sustancial de sociedad afirma un constructivismo siempre provisorio e interminable de lo social, las derivas del "análisis del discurso" recalaron en dos puertos de investigación. En primer lugar en los "estudios culturales", donde convivió junto a la deconstrucción y a una lectura discursivista del psicoanálisis lacaniano. En segundo lugar en las indagaciones sobre el "discurso político", en una comprensión llana del "discurso" como conjunto de enunciados donde se establecen "fronteras hegemónicas", "demandas", etc. El rasgo característico de ambas figuras epistémicas del postmarxismo laclauiano es la evasión de un estudio más complejo donde quehaceres lingüísticos, prácticas no solo discursivas, movimientos estructurales, sean conjugados en fórmulas menos atenidas a un nuevo reduccionismo.

La relación de Laclau con el marxismo es una cuestión crucial pues éste tiene razón cuando sostiene, junto a Mouffe, que su concepción es de alguna manera también un postmarxismo. ${ }^{7}$ El Marx de Laclau es sobre todo el del "Prefacio" a la Crítica de la economía politica de 1859 donde se esboza una teoría general de la historia a través de diferentes formas de "producción social de la existencia". Las relaciones objetivas entre los seres humanos se transforman por la presión del desarrollo de las fuerzas productivas sobre las relaciones sociales de producción, las que en su conjunto constituyen la base "real" sobre la que se eleva un "edificio" jurídico y político al que corresponden "formas de conciencia social" (Cohen, 1978; Hobsbawm, 2011). Es cierto que la referencia al "Prefacio" no aparece en toda su importancia en el libro de 1985, aunque surge cuando de él depende el cuestionamiento crucial de la separación (e incluso la autonomía relativa) de la base económica y la "superestructura" (Laclau y Mouffe, 2004 [1985]: 112-142). Reaparece

7. Los ensayos de desgajar al postmarxismo de la pregnancia conceptual del marxismo, por ejemplo subrayando las deudas con el "giro lingüístico" y el simbolismo, son poco convincentes. Por ejemplo Breckman (2013). 
preeminente cuando Laclau responde a la crítica de Norman Geras y en la reelaboración de su planteo en Nuevas reflexiones sobre la revolución de nuestro tiempo (2000 [1990]), el texto definitivo de abandono del marxismo. La "articulación" hegemónica que conduce a las "posiciones de sujeto" y al "pueblo" tiene como precondición la subversión del causalismo unívoco, no importa si se lo concibe al modo humeano o al althusseriano. ${ }^{8}$

Para Laclau, en la crítica de la metáfora marxiana de base y superestructura se dirime la suerte del marxismo como filosofia de la historia y de su capacidad para justificar una estrategia política. Además, agrega, su determinismo es incompatible con la fórmula del Manifiesto comunista de la historia como "historia de la lucha de clases". Es ante la soldadura del pensamiento de Marx con el texto de 1859, tamizado con el pasaje discordante del Manifiesto, que la invocación laclauiana a construir una concepción completamente diferente alcanza fuerza argumentativa. Del mismo modo, cuando en su ensayo de los años 90 "Más allá de la emancipación" rechaza los supuestos de las voluntades de revolución o liberación total, el "Prefacio" vuelve a rendir frutos como expresión de lo que el marxismo adeuda al "esencialismo" (Laclau, 1996 [1994]: pp. 27-30).

Laclau no señala que el "Prefacio" refiere a convicciones alcanzadas por Marx y Engels en sus años de activismo y aprendizaje acontecidos entre París y Bruselas (1844-1845), resumidos en la "concepción materialista de la historia" de La ideología alemana. No dice que esos esbozos son abandonados a la "crítica roedora de los ratones" (Gunn, 1992). Tampoco destaca que el "Prefacio" de 1859 es posterior a los resultados "metodológicos" alcanzados en los Grundrisse de 1857-1858, donde toda teoría transhistórica de la historia es cuestionada. También olvida la ambigüedad del fundamento "clasista" de la historia pues, según subrayó Adorno (1942), la aserción de la historia como historia de la lucha de clases no es un enunciado afirmativo -descriptivo de una visión general del devenir social humano- sino critico de la historia.

No me quiero detener aquí en una exégesis del pensamiento de Marx. Menciono la reconstrucción laclauiana por otra razón que hacer explícita sus dificultades hermenéuticas que calzan tan bien en la manera en que el joven Laclau de los años 60 comprendía el marxismo. Es importante

8. Adopto el concepto de subversión del vocabulario de Laclau y Mouffe, quienes entienden por ello la sobredeterminación que mina la presunta unidad significativa de un sistema construido diferencial y antagonísticamente. Mouffe y Laclau subvierten el "determinismo" de Marx al proponer una alternativa que conserva la tensión con lo impugnado. Por eso lo que pocos años antes había sido anunciado como una "revolución copernicana" de la teoría marxista (Laclau y Mouffe, 1981) derivó en una renuncia a sus problemas al definir una ontología social distinta. 
porque Laclau realiza una subversión de los conceptos atribuidos a un cierto Marx. Ese es un origen de su postmarxismo y, por lo tanto, acarrea en lo impugnado lo que subvierte. Por eso el postmarxismo de Laclau será la contracara del "Prefacio": pluricausal antes que dialéctico, formal antes que histórico, y descriptivo antes que crítico.

Una de las fortalezas de la refutación laclauiana del marxismo es que impacta en las explicaciones deterministas de la política socialista, según la cual el horizonte revolucionario se deriva de la posición específica de la clase obrera en las relaciones de producción. Es un accesible objeto de disección por Laclau, al que no se le hace dificil mostrar en ella el objetivismo ingenuo, la ausencia de especificidad en la práctica política y un esencialismo de clase. Ante ese marxismo empobrecido, cuando el marxismo deja de ser una teoría crítica para devenir una ciencia positiva, el postmarxismo logra desplegar su agudeza analítica.

Laclau cuestiona la metafisica de la economía como origen de la política, de la clase social como presencia, y del socialismo como teleología inherente al capitalismo. Esa operación teórica se mantiene deudora del modo de leer a Marx y al marxismo. Las derivas metafisicas de una subversión de la metafísica se observan con toda claridad en la obra posterior de Laclau y su propuesta mejor desarrollada: la teoría general del populismo. Con los ensayos de la década de 1990, sobre todo en Emancipación y diferencia (1996 [1994]), el formalismo laclauiano sedimenta como una teoría formalista y de un aliento acusadamente escolástico; esto ha sido observado desde un deconstruccionismo más culturalista (Bowman, 2007). Al mismo tiempo, expresivo de la complejidad de su factura, lo político constituye lo social pero es deudor del juego infinito de un lenguaje concebido en términos retóricos (Kaplan, 2010).

\section{El populismo y la consumación ahistórica del postmarxismo}

La publicación de La razón populista en 2005 produjo, no obstante, una torsión en la constelación conceptual de Laclau tal como se había configurado entre Hegemonía y estrategia socialista y Emancipación y diferencia. Todavía en sus ensayos de fines de la década de 1990 Laclau se hallaba embarcado en preocupaciones que lo retenían en la explicación del entramado equivalencial y la producción de una frontera política diferencial, el juego entre universalidad y "significante vacío" dentro del horizonte de un pluralismo democrático-radical. ${ }^{9}$

El libro populista de 2005 amalgamó una diversidad de debates: con

9. Si revisamos textos tales como Emancipación y diferencia, las discusiones con Butler y Zizek del 2000, o incluso los textos de sus cercanías intelectuales reunidos en The 
el peculiar "marxismo" de Slavoj Zizek que bregó por reintroducir las nociones de clase y economía, con la dualidad multitud/pueblo cincelada por Antonio Negri y Michael Hardt en Imperio, con la deriva queer de Foucault desplegada por Judith Butler, con el impacto de la filosofia política del Jacques Rancière de El desacuerdo, con las impostaciones lacanianas de la politica democrática que discutieron la ausencia del "afecto" en sus elaboraciones previas (Laclau, Butler y Zizek, 2003 [2000]; Laclau, 2008b; Stavrakakis, 2007). Con todo, la sintesis que dio lugar a esa colección de polémicas teóricas parciales que es La razón populista fue la aparición del chavismo en el paisaje de un renovado "populismo latinoamericano". La interpretación "populista" del kirchnerismo, una nominación ante la cual los kirchneristas no siempre se encuentran cómodos, fue un fenómeno secundario.

Eso no significa que desertara de sus reflexiones precedentes. Laclau profundizó en su nuevo libro una propuesta de desestabilizar la dicotomía entre la particularidad y la universalidad, figuras de la discursividad en que se dirime el quehacer de lo político. La razón populista desechó, una vez más, las controversias sobre la filiación del populismo en grupos sociales. La unidad mínima de su desarrollo está constituida por demandas de cualquier índole sin ningún privilegio social sustantivo. Laclau plantea que las demandas dirigidas a un núcleo estatal operan en sentido horizontal compitiendo o confluyendo, según sea el caso de que el núcleo satisfaga (o no) una u otra demanda. La articulación posibilita la aparición de una demanda galvanizadora entre un conjunto heterogéneo de exigencias constituyendo, a posteriori, un "pueblo" correlativo a la formación de una nueva frontera interna con el Estado $\mathrm{u}$ otro conjunto de demandas. Una de las demandas configura retroactivamente un nosotros popular antes inexistente, que delimita un otro (estatal, o social) antipopular.

De acuerdo al argumento de Laclau existen relaciones contingentes entre: 1) las demandas particulares, cuya relación equivalencial no va de suyo, pues la lógica de la diferencia (entre demandas) y la lógica de la equivalencia son heterogéneas; y 2) la aparición de una demanda coaguladora de una frontera respecto a un otro, lo que entraña un salto cualitativo -o hegemónico- no social sino político. El nudo del razonamiento consiste en que ese salto político constituye al "pueblo" como un efecto de institución hegemónica discursiva. Como en Hegemonía y estrategia socialista, Laclau entiende por "discurso" la coexistencia conflictiva entre una lógica relacional horizontal (diferencia/equivalencia) y una vertical

Making of Political Identities (Laclau, ed., 1994), la cuestión populista carece de relevancia salvo en la preocupación por el populismo derechista en la ex Yugoeslavia. 
(elevación de una demanda al privilegio de demanda-del-pueblo, que suele suponer la identificación apasionada con un líder).

Laclau propone que la lógica de construcción de las identidades colectivas populistas regula la lógica política como tal. Y si dicha lógica populista es "vaga" o "retórica", es porque todas las identidades son socialmente vagas y se constituyen en un crisol retórico. El paso de una demanda parcial al status de nudo articulador de una formación colectiva no es privilegio del populismo. Toda configuración política se alimenta de esa relación retórica básica que al nombrar la representatividad de esa demanda, imprime consistencia al conjunto de demandas democráticas, que así devienen populares (Laclau, 2005: 91).

El tranco teórico de La razón populista pretende ser rigurosamente trascendental, transhistórico. Subyacente en la aparente multiplicidad de las formas políticas hay una constante, a saber, la de las múltiples maneras de constituir al "pueblo" y proponer su representación. La peculiaridad del populismo es que utiliza al "pueblo" y no al ciudadano o a la clase. En el populismo no hay delegación en una entidad representativa, sino una presencia directa (esto es, retóricamente directa) a través del líder. Bajo este sol, el liberalismo, el fascismo o el socialismo no son esencialmente diferentes, pues también lidian con la representación de la heterogeneidad constitutiva de lo social. Sus distinciones se basan en la manera de intersectar las dinámicas de la diferencia y de la equivalencia. El populismo, al obedecer a una morfologia articulatoria pura entre esos polos, es decir, como relación entre significantes, carece de un sentido político concreto. Puede haber populismos progresistas o reaccionarios.

El libro de Laclau no provee ningún criterio teórico para realizar operaciones de discernimiento político. Su modelización conceptual carece de la facultad de distinguir entre la diversidad de los populismos, pero eso es justamente lo que una teoría del populismo debería ofrecer. Sería incorrecto decir que el autor es indiferente a las alternativas politicas mundiales. Laclau es un populista progresista, de una izquierda antiimperialista simpatizante de los regimenes nacionalistas con rasgos redistributivos. El asunto es que estas posiciones están desconectadas del tinglado conceptual de su teoria. Laclau se priva incluso del gesto kantiano de atisbar una idea regulativa, por lo cual debe responderse afirmativamente a la preocupación de Simon Critchley: “¿Hay un déficit normativo en la teoría de la hegemonía?” (en Critchley y Marchart [2008: cap. 6]).

La filosofia política de Laclau carece de una definición histórica de derecha e izquierda (estas son construidas discursiva y relacionalmente). La consecuencia, que no me parece convincente, es que la evaluación de un régimen político sólo puede ser resuelta al modo decisionista. Esta 
consecuencia había sido anticipada antes del retorno del populismo a propósito del diálogo de la teoría de la hegemonía con la deconstrucción (Laclau, 1998). Es la contracara del formalismo y ahistoricidad de los conceptos laclauianos, los que por lo tanto redundan en una posición metafisica. El discurso populista cede en historicidad al hacerse transhistórico, externo a cualquier determinación que no sea la de su propia lógica. En esa deriva transhistórica confluye con autores postmarxistas como Alain Badiou y Jacques Rancière. Laclau (2008c: 398) propone que la ahistoricidad de la "hegemonía" es una proyección moderna sobre otras épocas, tal como argumenta Marx en los Grundrisse respecto de que el grado de abstracción alcanzado por las categorias capitalistas arroja luz sobre otros periodos. Sin embargo, mientras para Marx eso no funda un "marxismo", para Laclau sí erige una teoría generalizada del populismo.

\section{Conclusiones: intelectuales y politica}

En este recorrido de la actuación político-intelectual de Ernesto Laclau he intentado compulsar cuánto de su derrotero fue un hecho social, colectivo, donde el pasaje al postmarxismo fue vivido como una asunción de la democracia capitalista -que en Laclau y tantos otros de su generación ha pasado a ser la democracia sin más- como horizonte insuperable de la estrategia de izquierda. Pero también he señalado las continuidades de un planteo fundamental, de una crítica politicista del marxismo, de una lectura equivocada de Marx, ya ambiguamente presente en el corazón de la Izquierda Nacional. No es que Laclau estuviera todo allí, en el esquema elaborado por Ramos y Spilimbergo, pues justamente la peculiaridad histórica de su itinerario consiste en seguir las metamorfosis del politicismo desde una fundación economicista a otra discursivista.

La pertenencia "histórica" del sujeto Laclau sugiere meditar el teorema de Tarcus que sostiene la eficacia represiva de las estructuras partidarias tradicionales de la izquierda argentina respecto de la creatividad intelectual individual (Tarcus, 1996: 18). La obra que hizo famoso a Laclau es impensable sin la experiencia formativa de su acción orgánica en el PSIN y él nunca ha renegado de su deuda con las enseñanzas juveniles. Separar una obra partidaria de la otra postpartidaria, como si finalmente su potencialidad habria advenido por haberse "liberado" de la organización, y alcanzado su "creatividad", supone una afirmación especulativa e incomprobable. Sucede lo contrario pues medio siglo más tarde el Laclau anciano sigue respirando en el microclima ideológico de su juventud. Él ha reiterado infatigablemente cuánto su postmarxismo le debe a los años formativos. Ante una pregunta sobre 
las razones que lo condujeron de sus "primeros pasos vacilantes" al postmarxismo, Laclau respondió que no veía una discontinuidad en su trayectoria. Agregó que cuando regresó a Buenos Aires en 1984 notó con sorpresa al leer sus editoriales de Lucha Obrera de veinte años antes que "la lucha socialista ya se planteaba en términos de la hegemonización de las tareas democráticas por parte de la clase obrera" (Laclau, 2000 [1990]: 187-188). Por cierto que la visión retrospectiva de Laclau no es del todo exacta. En los años 60 el sujeto era el partido obrero y el objetivo mediato la transformación revolucionaria. Y la clarividencia juvenil no lo es tanto de concepción política "gramsciana" como de una persistente búsqueda de parasitar la identificación popular del peronismo. Por otra parte el contexto de la discutible legitimidad del gobierno de Illia y luego el rechazo global a la dictadura de Onganía eliminaban la estrategia reformista desarrollada en los años 80 (Laclau, 1965a y 1966). Lo que me interesa destacar, sin embargo, es que si la continuidad es problemática, la discontinuidad lo es aún más. La tesis de la continuidad en la Izquierda Nacional es compatible con matices en sus énfasis teóricos, tales como unos años 70 "gramscianos", unos años 80 "postgramscianos" y unas últimas décadas de mayor inclinación "lacaniana" (Torfing, 1999).

La perseverancia de la travesía teórico-política de Laclau es también la de una variante de la izquierda del siglo XX. Comprender su esfuerzo exige hacer justicia a la insistencia con que bregó por esclarecer las inviabilidades reiteradas de encabalgarse con las fuerzas "progresistas" e incidir en su orientación. La política de la Izquierda Nacional quiso durante tres décadas acercarse "críticamente" al peronismo para "hegemonizarlo" y siempre fue, en los momentos más exitosos, un apéndice del polimórfico movimiento liderado por Perón. Impotente para incidir en la clase trabajadora y en sus dirigencias más inmediatas, la tendencia efectiva consistió en influir en las élites políticas del peronismo. Todo ello coincidió en una coyunda dificil donde la impotencia fue quebrando los ánimos. Llevó al líder histórico del sector, Ramos, a lanzarse en los años 80 con furia nacionalista en los brazos de la corporación militar. Otros como Spilimbergo y Norberto Galasso trataron de continuar con el planteo del "apoyo crítico" al "movimiento nacional", y solo tuvieron alguna repercusión como grupo propagandístico marginal. Laclau captó a mediados de los años 60 esa inviabilidad y se alejó de la vida política organizada. Sin embargo no abandonó sus convicciones más profundas y todavia hoy deplora las argumentaciones "ultraizquierdistas" que pregonan la revolución, un término político inútil según Laclau por sus connotaciones utópicas y externas a toda constitución hegemónica. Índice de su permanencia en la Izquierda Nacional es que Laclau jamás se consideró peronista. Todavía hoy su apoyo al kirchnerismo ostenta una 
veta de perspicacia intelectual al destacar que el gobierno de Cristina Fernández excede la "experiencia histórica" del peronismo.

Dos admiradores de la obra de Laclau han resumido bien su nervio conceptual: "La obra de Ernesto Laclau es uno de los intentos contemporáneos más innovadores e influyentes de revivir y rearticular el pensamiento político en una época en que sus fundamentos se han vuelto cada vez más inciertos" (Critchley y Marchart, comps., 2008: 15). Solo añadiría dos rasgos a esa fórmula.

En primer lugar pienso que Laclau ha tratado de reconstruir el pensamiento político de izquierda. Laclau no es responsable de la proliferación de "usos de Laclau" donde la definición de una postura de izquierda es completamente irrelevante. Peronistas, populistas en general, socialistas reformistas, e incluso liberales moderados, además de los eclecticismos más ligeros, practican empleos no políticos de Laclau. Si bien en la industria universitaria del laclauismo suele darse por supuesta la necrosis del marxismo (pues el punto de partida es "postmarxista"), el autor ha ingresado a un mercado academicista donde su nombre y textos circulan entre otros nombres y textos igualmente prestigiosos, también útiles para "fundamentar" papers. La exterioridad a la orientación socialista es manifiesta en sus discipulos (por ejemplo: Critchley y Marchart, comps., 2008; Stavrakakis, 1999 y 2007).

En segundo lugar estimo que la ausencia de fundamentos no significa que ellos sean tan inciertos como discursivamente articulables, justamente por su contingencia. De tal modo que el derrumbe de los fundamentos no implica para Laclau una convicción pesimista sino más la celebración de la apertura de lo político, una peculiaridad de la democracia. Laclau ha anunciado un libro al respecto, La universalidad elusiva, en el que discutirá con Alain Badiou cómo la ruptura de la "situación" puede ser producida "hegemónicamente".

La actuación de Laclau en los ámbitos kirchneristas argentinos no es un testimonio concluyente al respecto. No solo porque los efectos de su obra exceden el espacio argentino, sino sobre todo porque tal evaluación incurre en la falacia ad hominem de sintetizar en sus acciones finitas las potencialidades incalculables de los conceptos por él forjados. Pero traer al debate su actuación concreta es relevante porque el propio Laclau ha insistido en la vocación práctica de su quehacer teórico. Él pretende "hacer cosas con palabras", y entre ellas está la acción política anti status quo, aunque no anticapitalista. Laclau es un enigma teórico y práctico pues no es evidente cómo transitó el camino que lo llevó del final de Hegemonía y estrategia socialista convocante de una "nueva izquierda" y la "radicalización de la democracia" hasta su actuación crepuscular de apoyo técnico a los neodesarrollismos populistas.

Dentro del esquema kirchnerista, Laclau provee una legitimidad 
teórica e intelectual, pero no incide en la acción real a pesar de que no subestimo la efectividad propagandística de su palabra en los ámbitos universitarios. Aunque sostiene que el kirchnerismo es la "izquierda real" en la Argentina, su juicio es unilateral y poco convincente en la medida en que visibiliza sus dimensiones progresivas (democratización formal del acceso a medios de comunicación, matrimonio igualitario, moderada distribución de ayuda social básica, enjuiciamiento de los militares perpetradores de violaciones a los derechos humanos), pero omite aspectos ambiguos o francamente negativos como el impuesto al salario, el extractivismo, la oposición a la despenalización del aborto, la reproducción de la vieja política elitista, abandonando así, Laclau, toda crítica de izquierda -descartada la proyección socialista- y atenuando su capacidad de convencimiento fuera de los creyentes (Laclau, 2011a y 2011 b).

En ese sentido Laclau es uno más -aunque el de mayor visibilidad internacional-de los proclamados intelectuales que se confinan a proveer combustible argumentativo a decisiones adoptadas en otro lugar, en el territorio donde la dirigencia kirchnerista decide qué hacer. Repite así el drama de su mentor: Ramos quiso ser el cerebro de Perón, mientras Laclau pretendió ser el teórico de Cristina Fernández. Por eso afirmé la inconveniencia de insistir demasiado sobre los cursos falibles de las decisiones personales, pues perfectamente podria suceder que las deficiencias políticas de Laclau fueran las suyas biográficas, y no las de su obra teórica ni las de su familia ideológica. Es que en efecto, hay una fundamentación más sustantiva para cerrar este análisis: la estatura intelectual del postmarxismo. Por cierto que el marxismo requiere revisiones y reinterpretaciones, nuevos análisis y conceptos alrededor del núcleo irrenunciable de la crítica de la lógica del capital. No opongo al postfundacionalismo discursivista de Laclau una vigencia del marxismo como metafísica socioeconómica de la política. Pero su pensamiento está conceptualmente cosido a la operación de crítica de Marx, avanzada con vigor desde Hegemonía y estrategia socialista.

El marxismo del joven Laclau fue un marxismo tradicional, desgarrado entre el "materialismo histórico" de los modos de producción y la historia como secuencia de luchas de clases. En ese sentido no se separó de la comprensión positiva del marxismo, es decir, del marxismo como teoría objetivista, predominante en la Argentina de los años 60. Un problema de Laclau fue, y lo es hasta hoy, que su diagnóstico pesimista respecto del marxismo siempre tuvo en mente ese marxismo tradicional, al que quiso corregir primero a través de Althusser y Gramsci, y luego de su apartamiento del marxismo sustituyó con Derrida y Lacan.

Fundamentar una teoría como subversión de una interpretación inadecuada de Marx solo puede conducir a un resultado insatisfactorio, 
pues tal teoría permanece aprisionada en los términos equívocos de los que brota. Este es un cimiento del fracaso laclauiano en su proeza de inventar el postmarxismo: continúa adherido, rechazándola, a una comprensión deficiente de Marx. ${ }^{10}$

Si he querido ofrecer este recorrido de Laclau es porque valoro la constancia de su programa teórico y no celebro que al subvertir una interpretación metafisica tradicional de Marx continuase en el terreno de la metafísica, solo que refigurada a través de la formalización. De allí las consecuencias ahistóricas de su pensamiento y la mengua con que ha sostenido el aliento del subtítulo de un texto reciente: "Por un nuevo horizonte de la política" (Laclau, 2008a: 8). Y no creo que haya que celebrar, como en la Schadenfreude, la clausura del horizonte teórico-político de una Izquierda Nacional cuyo porvenir estratégico fue cancelado hace cuarenta años. Pero es notorio que el proyecto laclauiano de una subversión discursivista del marxismo no rindió los frutos prometidos. No recompuso la estrategia socialista ni hizo más viable una práctica "gramsciana" de hegemonización revolucionaria. No neutralizó las derivas esencialistas de la positivización del marxismo ni entrevió otra manera convincente de radicalizar la democracia. Su interés descansó en las consecuencias para el "análisis del discurso", ya en sede estrictamente académica. Pero asi se desvió de las aspiraciones emancipatorias que lo impulsaron.

Esa deriva fue más que solo suya, pues participó de las dificultades sistemáticas de la Izquierda Nacional, un esquema estratégico que Laclau jamás se atrevió a repensar. Por eso recientemente el agudo teórico del significante vacío tuvo buenos motivos para consagrar a Ramos como "el pensador político argentino de mayor envergadura que el país haya producido en la segunda mitad del siglo XX" (Laclau, 2012). Es que Laclau compartió el destino histórico de su corriente ideológica. En la mencionada deriva subordinada a una versión del peronismo insistió lo real de una estrategia malograda: la cándida convicción de atesorar mayores luces teóricas que una voluntad política reformista a la que se pliega pero intenta dirigir, un sometimiento que ningún denuesto contra la "ultraizquierda" consigue velar. La estación terminal del pensamiento de Laclau es la clave de bóveda con que el firmamento de la teoría consume el itinerario desolado de la Izquierda Nacional.

10. Con esto me abstengo de afirmar dos cosas que requeririan otras elaboraciones: que la crítica al marxismo tradicional es innecesaria y que la teoría política de la izquierda obrerista es correcta. 


\section{Bibliografia}

Adorno, Theodor W. (1942), "Reflexionen zur Klassentheorie", en Gesammelte Schriften, Francfort del Meno: Suhrkamp, 1972, vol. 8, pp. 373-391.

Belloni, Alberto (1960), Del anarquismo al peronismo. Historia del movimiento obrero argentino, Buenos Aires: Peña Lillo.

Bergel, Martín, Mariana Canavese y Cecilia Tossounian (2004-2005), "Práctica política e inserción académica en la historiografia del joven Laclau", Politicas de la Memoria, No 5, pp. 149-158.

Borón, Atilio (1996), “¿Post-marxismo? Crisis, recomposición o liquidación del marxismo en la obra de Ernesto Laclau", Revista Mexicana de Sociología, vol. $58, \mathrm{~N}^{\circ} 1$, pp. 17-42.

Boucher, Geoff (2008), The Charmed Circle of Ideology. A Critique of Laclau and Mouffe, Butler and Zizek, Melbourne: re.press.

Bowman, Paul (2007), Post-Marxism versus Cultural Studies. Theory, Politics and Intervention, Edimburgo: Edinburgh University Press.

Breckman, Warren (2013), Adventures of the Symbolic. Post-Marxism and Radical Democracy, Nueva York: Columbia University Press.

Cohen, Gerald (1978), Karl Marx's Theory of History. A Defence, Oxford: Oxford University Press.

Critchley, Simon y Olivier Marchart (comps.) (2008), Laclau. Aproximaciones criticas a su obra, Buenos Aires: Fondo de Cultura Económica.

Galasso, Norberto (1983), La Izquierda Nacional y el FIP, Buenos Aires: Centro Editor de América Latina.

- (2007), Aportes criticos a la historia de la izquierda argentina. Socialismo, peronismo e izquierda nacional, Buenos Aires: Nuevos Tiempos.

Geras, Norman (1987), "Post-Marxism?", New Left Review, No 163, mayojunio, pp. 40-82.

- (1988), "Ex-Marxism without Substance: Being a Real Reply to Laclau and Mouffe", New Left Review, N 169, mayo-junio, pp. 34-61.

Gunn, Richard (1992), "Against Historical Materialism: Marxism as FirstOrder Discourse”, en W. Bonefeld, R. Gunn y K. Psychopedis (eds.), Open Marxism, vol. 2, Londres: Pluto, pp. 1-45.

Herrera, Carlos M. (2011), "El Partido Socialista de la Revolución Nacional, entre la realidad y el mito", Revista Socialista, N ${ }^{\circ} 5$, pp. 33-47.

Hobsbawm, Eric J. (2011), "Marx on Pre-Capitalist Formations", en How to Change the World. Reflections on Marx and Marxism, Londres-New Haven: Yale University Press, pp. 127-175.

Kaplan, Michael (2010), "The Rethoric of Hegemony: Laclau, Radical Democracy, and the Rule of Tropes", Philosophy and Rethoric, vol. 43, $\mathrm{N}^{\circ}$ 3, pp. 253-283.

Laclau, Ernesto (1960), "Un impacto en la lucha de clases. El proceso inmigratorio argentino", Situación, n 4, junio, pp. 15-19.

- (1963), "Nota sobre la historia de las mentalidades", Desarrollo Económico, $\mathrm{N}^{\circ} 1 / 2$, pp. 303-312. 
- (1964a), "La crisis del sindicalismo puro", Lucha Obrera, año 1, $\mathrm{N}^{\circ}$ 2, 7 de octubre, p. 1.

- (1964b), "Historia melancólica del Ejército azul", Lucha Obrera, año 1, No 3, 14 de octubre, p. 1.

- (1964c), "Illia o la filosofia de la tortuga", Lucha Obrera, año 1, No 4, 21 de octubre, p. 1.

- (1964d), "Presupuesto universitario y luchas nacionales", Lucha Obrera, año $1, \mathrm{~N}^{\circ} 5,28$ de octubre, p. 1.

- (1964e), "La UCRP. Entre la espiga y la espada", Lucha Obrera, año 1, No 6,4 de noviembre, p. 1.

- (1964f), "Pensamiento marxista e historia argentina. Conciencia histórica e izquierdismo pequeño burgués", Izquierda Nacional, $\mathrm{N}^{\circ}$ 6, pp. 3-9.

- (1965a), "Concurrencia electoral y política revolucionaria", Lucha Obrera, año $1, \mathrm{~N}^{\circ} 10,29$ de enero.

- (1965b), "Termina la pax radical", Lucha Obrera, año 2, No 15, 15 de noviembre.

- (1966), "Partido revolucionario y realidad argentina", Lucha Obrera, año $3, \mathrm{~N}^{\circ} 19,1^{\circ}$ de enero.

- (1969), "Modos de producción, sistemas económicos y población excedente. Aproximación histórica a los casos argentino y chileno", Revista Latinoamericana de Sociología, $\mathrm{N}^{\circ}$ 5, pp. 276-315.

- (1971), "Feudalism and Capitalism in Latin America", New Left Review, $\mathrm{N}^{\circ}$ 62, pp. 19-55, reproducido en AA. VV., Modos de producción en América Latina, Córdoba: Pasado y Presente, 1973, pp. 33-57.

- (1978), Politica e ideología en la teoría marxista. Capitalismo, fascismo, populismo, México: Siglo Veintiuno.

- (1996 [1994]), Emancipación y diferencia, Buenos Aires: Ariel.

- (1998), "Deconstrucción, pragmatismo y hegemonía", en Chantal Mouffe (comp.), Deconstrucción y pragmatismo, Buenos Aires: Paidós, pp. 123145.

- (2000 [1990]), Nuevas reflexiones sobre la revolución de nuestro tiempo, Buenos Aires: Nueva Visión.

- (2002), "Política de la retórica", en Misticismo, retórica y politica, México:

Fondo de Cultura Económica, pp. 57-101.

- (2005), La razón populista, Buenos Aires: Fondo de Cultura Económica.

- (2008a), Debates y combates. Por un nuevo horizonte de la política, Buenos

Aires: Fondo de Cultura Económica.

- (2008b), “¿Por qué construir al pueblo es la principal tarea de una política radical?”, en Laclau (2008a), pp. 13-64.

- (2008c), "Atisbando el futuro", en Critchley y Marchart (2008), pp. 347404.

- (2011a), "La real izquierda es el kirchnerismo", Página/12, 2 de octubre.

- (2011b), "En América Latina los populismos son de izquierda", entrevista, Revista Socialista, $\mathrm{N}^{\circ}$ 5, pp. 11-17. 
- (2012), "Ramos en la historia de la izquierda argentina", prefacio a Regali (2012).

Laclau, Ernesto (ed.) (1994), The Making of Political Identities, Londres: Verso.

Laclau, Ernesto y Chantal Mouffe (1981), "Socialist Strategy - Where Next?”, Marxism Today, enero, pp. 17-21.

- (1987), "Post-Marxism without Apologies", New Left Review, No 166, noviembre-diciembre, pp. 79-106; reproducido en Laclau (2000).

- (2004 [1985]), Hegemonía y estrategia socialista, Buenos Aires: Fondo de Cultura Económica.

Laclau, Ernesto, Judith Butler y Slavoj Zizek (2003 [2000]), Contingencia, hegemonía, universalidad. Diálogos contemporáneos en la izquierda, Buenos Aires: Fondo de Cultura Económica.

Laclau (p), Ernesto (1921), Filosofía politica argentina, Buenos Aires: Nosotros.

- (1928), La formación politica de la sociedad argentina, Buenos Aires: Araujo.

Lefort, Claude (1990 [1981]), La invención democrática, Buenos Aires: Nueva Visión.

Marchart, Oliver (2009), El pensamiento politico posfundacional. La diferencia politica en Nancy, Lefort, Badiou y Laclau, Buenos Aires: Fondo de Cultura Económica.

Meiksins Wood, Ellen (1986), The Retreat from Class. A New "True" Socialism, Londres: Verso.

Methol Ferré, Alberto (1961), La izquierda nacional en la Argentina, Buenos Aires: Coyoacán.

Mouffe, Chantal (ed.) (1979), Gramsci and Marxist Theory, Londres: Routledge.

Mouzelis, Nicos (1988), "Marxism or Post-Marxism?", New Left Review, No 167, enero-febrero, pp. 107-124.

Portantiero, Juan Carlos (1983), Los usos de Gramsci, Buenos Aires: Folios.

Ramos, Jorge Abelardo (1964), La lucha por un partido revolucionario, Buenos Aires: Pampa y Cielo.

Regali, Enzo (2012), Abelardo Ramos, la Izquierda Nacional y la Nación Latinoamericana, Buenos Aires: Ciccus.

Sim, Stuart (2008), Post-Marxism. An Intellectual History, Londres y Nueva York: Routledge.

Smith, Anna Marie (1998), Laclau and Mouffe. The Radical Democratic Imaginary, Londres y Nueva York: Routledge.

Spilimbergo, Jorge R. (1962), La cuestión nacional en Marx, Buenos Aires: Octubre.

- (2010 [1964]), Clase obrera y poder. Tesis politicas del Tercer Congreso del Partido Socialista de la Izquierda Nacional, Buenos Aires: Ediciones del Sur. 
Stavrakakis, Yannis (1999), Lacan and the Political, Londres: Routledge. - (2007), La izquierda lacaniana, Buenos Aires: Fondo de Cultura Económica.

Tarcus, Horacio (1996), El marxismo olvidado en la Argentina. Milcíades Peña y Silvio Frondizi, Buenos Aires: El Cielo por Asalto.

Therborn, Göran (2008), From Marxism to Post-Marxism?, Londres y Nueva York: Verso.

Torfing, Jacob (1999), New Theories of Discourse. Laclau, Mouffe and Zizek, Oxford: Blackwell.

Tortti, María Cristina (2009), El "viejo" partido socialista y los orígenes de la "nueva" izquierda (1955-1965), Buenos Aires: Prometeo.

$$
* * *
$$

Resumen: La obra marxista y postmarxista de Ernesto Laclau es interpretable en el derrotero de la Izquierda Nacional argentina. Esa opción populista asumida en 1963 perduró como su horizonte teórico-estratégico. A lo largo de su recorrido, el pensamiento teórico de Laclau se supeditó a una identidad política de arraigo masivo, el peronismo, sin incidir en el proyecto gramsciano de una "reforma intelectual y moral" que habilitase una hegemonía "obrera y popular" elevándola al plano "nacional". Sus sofisticaciones filosóficas persisten en los pliegues del proyecto de la Izquierda Nacional desmantelado desde 1973.

Palabras clave: Ernesto Laclau - Izquierda Nacional - Postmarxismo - Teoria politica

Abstract: Ernesto Laclau's Marxist and Postmarxist works are best understood when inscribed in Argentina's National Left. This populist current has continued to underpin his strategic horizons since 1963. In the course of his working life, Laclau's theoretical thought became subservient to Peronism, a political identity amply rooted in the working class. He remained aloof to a Gramscian type "moral and intellectual reform" that aspires to engender a "popular and working class" hegemony through a national framework. His sophisticated philosophical contemplations remain imprisoned by the twists and turns of the National Left's projections, whose strategy collapsed in 1973.

Keywords: Ernesto Laclau - National Left - Postmarxism - Political Theory

Recepción: 14 de junio de 2013. Aprobación: 28 de julio de 2013 